Revue

Revue de l'histoire des religions

de Ihistoire des religions

$1 \mid 2014$

Varia

\title{
Albrecht Dihle, Ausgewählte kleine Schriften zu Antike und Christentum
}

Münster, Aschendorff Verlag, 2013

\section{Sylvain Destephen}

\section{(2) OpenEdition}

Journals

Édition électronique

URL : http://journals.openedition.org/rhr/8206

DOI : $10.4000 /$ rhr.8206

ISSN : 2105-2573

Éditeur

Armand Colin

\section{Édition imprimée}

Date de publication : 1 mars 2014

Pagination : 127-130

ISBN : 978-2200929107

ISSN : 0035-1423

Référence électronique

Sylvain Destephen, «Albrecht Dihle, Ausgewählte kleine Schriften zu Antike und Christentum », Revue de I'histoire des religions [En ligne], 1 | 2014, mis en ligne le 24 septembre 2014, consulté le 22 septembre 2020. URL : http://journals.openedition.org/rhr/8206 ; DOI : https://doi.org/10.4000/rhr.8206

Ce document a été généré automatiquement le 22 septembre 2020.

Tous droits réservés 


\section{Albrecht Dihle, Ausgewählte kleine Schriften zu Antike und Christentum}

Münster, Aschendorff Verlag, 2013

Sylvain Destephen

\section{RÉFÉRENCE}

Albrecht Dihle, Ausgewählte kleine Schriften zu Antike und Christentum, Münster, 2013

(Jahrbuch für Antike und Christentum. Ergänzungsband, 38), 28 cm, 430 p., $69 €$, ISBN

978-3-402-10806-2.

1 Après deux volumes de mélanges offerts en 1993 et 2008, le philologue, historien, philosophe et patristicien Albrecht Dihle (A.D.) a été honoré, à l'occasion de son quatre-vingt-dixième anniversaire célébré en 2013, par ce recueil d'une quarantaine de ses publications. Parmi celles-ci figurent les recensions des livres de Johannes Leipoldt, Griechische Philosophie und frühchristliche Askese, Berlin, 1961, Loveday Alexander, The Preface to Luke's Gospel: Literary Convention and Social Context in Luke 1.1-4 and Acts 1.1, Cambridge, 1993, et Willi Braun, Feasting and Social Rhetoric in Luke 14, Cambridge, 1995, réimpr. 2005. Ces scripta varia minora sont édités par l'historien de l'Église Georg Schöllgen, actuel directeur de l'Institut Franz Josef Dölger qui assure, à Bonn, la publication des volumes du Reallexikon für Antike und Christentum (RAC), auquel A. D. a collaboré pendant quarante ans, comme G. Schöllgen le rappelle dans son avant-propos en forme d'hommage. L'auteur a par ailleurs rédigé une demi-douzaine de notices biographiques d'historiens, de rhéteurs et de grammairiens pour la Paulys Realencyclopädie der classischen Altertumswissenschaft.

2 À la différence des Ausgewählte kleine Schriften d'Ernst Dassmann, publiés dans la même série en 2011 (voir le compte rendu dans la RHR, 2012, 3, p. 429-432), la liste des travaux nombreux d'A. D. fait défaut. Si, dans le cadre de cette recension, il serait vain et déplacé d'évoquer sa centaine d'articles, il n'est pas davantage utile de dresser l'inventaire exhaustif de sa quarantaine de livres et de fascicules, écrits seul ou en 
collaboration, même si certains restent marquants. Les plus célèbres, dans et hors du monde germanophone, sont sans doute une histoire de la littérature grecque d'Homère à l'époque hellénistique, plusieurs fois rééditée et augmentée, et un panorama de la littérature gréco-latine de la période impériale, d'Auguste à Justinien. L'un et l'autre de ces ouvrages ont fait l'objet d'une traduction anglaise, mais non française. Son livre Die Griechen und die Fremden, paru à Munich en 1994, a également été traduit trois ans plus tard en italien sous le titre I Greci e il mondo antico. D'autres monographies de nature littéraire ou historiographique manifestent l'intérêt de l'auteur pour la biographie historique, la philosophie antique, en particulier la notion d'éthique, et les échanges culturels du monde grec avec l'Orient. Certains des articles ici rassemblés associent ces thématiques à l'histoire du christianisme ancien qui, de toute évidence, constitue un aspect essentiel de l'œuvre multiforme d'A. D. Notons une étude sur les relations entre les Évangiles et le genre biographique, parue en 1983 à Tübingen dans les actes d'un colloque sur le Nouveau Testament (p.114-137), une autre relative au sort de l'enseignement de la philosophie dans l'Église ancienne, publiée en 1987 dans les mélanges posthumes offerts à l'aristotélicien Paul Moreaux (p.164-177), enfin une dernière étude, parue aux États-Unis en 1998 et cette fois en anglais, concernant la diffusion du christianisme sur les côtes de l'Inde, mais aussi de l'Éthiopie et de l'Arabie (p. 314-325).

3 Ce tropisme géographique original est inattendu de la part d'un philologue classique, intéressé par Homère et Euripide, Tacite et Varron. On doit à A. D. une copieuse notice sur l'Inde dans le RAC, 18 (1997), p. 1-56. Cet intérêt singulier a pris la forme, dès 1965, d'une synthèse sur la présence grecque en mer Rouge qui a paru dans les travaux de recherche de la Société scientifique de Rhénanie-Westphalie. Absente du recueil, sans doute en raison de sa taille (une centaine de pages) et de son contexte historique "païen", cette étude est évoquée dans le réexamen par A.D. de l'ambassade de l'évêque et missionnaire arien Théophile l'Indien, parti évangéliser le royaume himyarite (actuel Yémen), sous le règne de Constance II (337-361). Cet article, paru en français à Leyde en 1989, dans les actes d'une table ronde consacrée à l'Arabie préislamique, figure en bonne place dans le recueil (p. 201-206). En 1969, l'A. avait déjà offert à ce sujet une étude, en allemand, à un autre spécialiste d'Aristote prématurément disparu, Rudolf Stark, dont les mélanges constituent le quatrième volume de la collection Palingenesia de Wiesbaden.

4 À la différence du recueil d'articles offert à E. Dassmann, le présent livre a évité de regrouper en chapitres thématiques les articles réédités et suit une stricte disposition chronologique. L'abondance et la diversité des travaux d'A. D. ont permis à l'éditeur de réussir le tour de force de sélectionner des articles, publiés entre 1952 et 2011, qui présentent une succession assez cohérente des domaines étudiés par l'auteur au cours de sa carrière universitaire à Cologne puis à Heidelberg où il est devenu professeur émérite en 1989. L'ouvrage débute par une étude (p.1-14), à la croisée de l'épistolographie avec l'histoire des mentalités, intitulée "Antike Höflichkeit und christliche Demut ", publiée en 1952 dans les Studi italiani di filologia classica. Cet article est suivi d'une demi-dizaine d'autres qui abordent les théories politiques de la doctrine paléochrétienne et leurs développements dans l'Antiquité tardive. Le deuxième quart du livre rassemble des études qu'il est tentant, mais sans doute un peu réducteur, de placer dans la catégorie de l'histoire des idées. Un article est ainsi consacré aux concepts de progrès, d'âge d'or originel et donc de déclin, définitif ou cyclique (p. 178-191). La pensée surtout hellénistique y bénéficie d'un traitement de choix, 
presque aux dépens de la patristique, réduite à des figures marquantes des II $^{\mathrm{e}}-\mathrm{III}{ }^{\mathrm{e}}$ siècles, comme Clément d'Alexandrie ou Origène.

5 Les articles publiés depuis les années 1990, et rassemblés dans la seconde moitié des Ausgewählte kleine Schriften, attestent un intérêt marqué pour les Pères de l'Église, qui n'ont toutefois pas détourné $\mathrm{A}$. D. de sa passion première pour la philologie. Parmi les auteurs chrétiens de langue grecque sont étudiés Grégoire de Nysse et la question de la possibilité ou de l'impossibilité de connaître la perfection, Synésios de Cyrène et le concept de conscience individuelle, enfin Théodoret de Cyr et sa défense du culte des martyrs. Pour le versant latin, il s'agit de Tertullien et sa doctrine de la double volonté divine et d'Augustin en relation avec sa théologie trinitaire. Dans chaque cas, à l'exception de Théodoret de Cyr (p. 309-313), la littérature patristique est envisagée comme un répertoire de sources qui servent moins à approfondir la connaissance du dogme et reconstituer l'histoire religieuse de l'Antiquité tardive, qu'à embrasser et illustrer l'horizon plus vaste et presque intemporel de l'histoire de la pensée. Cette approche intellectuelle et conceptuelle de la littérature chrétienne, replacée par volonté de comparaison et souci de démonstration dans l'évolution générale de l'hellénisme et de la philosophie antique, se manifeste à d'autres reprises dans les travaux les plus récents de l'auteur qui figurent à la fin de ce recueil. Deux articles, publiés en 1999 et 2009 (p. 358-367 et 409-421), sont consacrés à la question de la réception dans le christianisme ancien de la culture et de la philosophie grecques. Ces deux héritages, malgré la religiosité qui tend à les caractériser pendant le Haut- et surtout le Bas-Empire, ont été assimilés et conservés par les Pères de l'Église.

Il faut sans doute expliquer l'absence de certains articles d'A. D. intéressant l'histoire du christianisme par la taille réduite de ces scripta varia par rapport à ceux offerts, dans la même collection, à E. Dassmann. Il convient de citer une étude relative aux changements vestimentaires dans l'État et surtout l'Église du Bas-Empire, « Das Gewand des Einsiedlers Antonius ", in Jahrbuch für Antike und Christentum, 22, 1979, p. 22-29, une autre dédiée à la pensée religieuse, éthique et cosmogonique de Bardesane d'Édesse dans les mélanges offerts en 1979 à l'historien des religions Carl Andresen, enfin une dernière étude sur les concepts de libre arbitre et de destin dans l'Antiquité tardive, parue en 1989 dans la Revue de théologie et de philosophie, et où A. D. s'intéresse à nouveau à la position de Bardesane. Ces oublis sont compensés par la présence, dans le recueil (p. 207-214), d'un article en anglais qui examine la place de l'astrologie dans la doctrine chrétienne de cet auteur syriaque, peut-être influencé par l'enseignement des mages chaldéens. Ce dernier exemple achève d'illustrer l'intérêt montré par A. D., tout au long de sa carrière exemplaire, pour les questions d'influence culturelle par-delà les langues et les périodes.

\section{AUTEURS}

\section{SYLVAIN DESTEPHEN}

Université Paris Ouest - Nanterre La Défense 